\title{
Hemispheric asymmetry of liking for representational and abstract paintings
}

\author{
Marcos Nadal $^{1} \cdot$ Susanna Schiavi $^{2} \cdot$ Zaira Cattaneo $^{2,3}$
}

Published online: 13 October 2017

(C) Psychonomic Society, Inc. 2017

\begin{abstract}
Although the neural correlates of the appreciation of aesthetic qualities have been the target of much research in the past decade, few experiments have explored the hemispheric asymmetries in underlying processes. In this study, we used a divided visual field paradigm to test for hemispheric asymmetries in men and women's preference for abstract and representational artworks. Both male and female participants liked representational paintings more when presented in the right visual field, whereas preference for abstract paintings was unaffected by presentation hemifield. We hypothesize that this result reflects a facilitation of the sort of visual processes relevant to laypeople's liking for art-specifically, local processing of highly informative object features-when artworks are presented in the right visual field, given the left hemisphere's advantage in processing such features.
\end{abstract}

Keywords Lateralization $\cdot$ Hemispheric dominance $\cdot$ Art . Liking $\cdot$ Aesthetics $\cdot$ Divided visual field

Aesthetic features of objects influence people's affective responses, decisions, and behavior towards them. They play a central role in consumers' choice of products $(\mathrm{Ho}, \mathrm{Lu}, \&$ Chen, 2016; Patrick, 2016; Reimann, Zaichkowsky, Neuhaus, Bender, \& Weber, 2010), financial decisions

Marcos Nadal

marcos.nadal@uib.es

1 Human Evolution and Cognition Group, IFISC, University of the Balearic Islands - CSIC, Palma, Spain

2 Department of Psychology, University of Milano-Bicocca, Milano, Italy

3 Brain Connectivity Center, C. Mondino National Neurological Institute, Pavia, Italy
(Townsend \& Shu, 2010), judgments of built environments (Choo, Nasar, Nikrahei, \& Walther, 2017; Kirk, Skov, Christensen, \& Nygaard, 2009; Vartanian et al., 2015) and natural environments (Balling \& Falk, 1982; Kaplan, 1992), and in attitudes, judgments, and behaviors toward other people (Kampe, Frith, Dolan, \& Frith, 2001; Leder, Tinio, Fuchs, \& Bohrn, 2010; Mende-Siedlecki, Said, \& Todorov, 2012). Understanding the cognitive and neural processes underlying the impact of such aesthetic features on people's choices, motivation, and behavior is the main aim of the cognitive neuroscience of aesthetics (Chatterjee \& Vartanian, 2014; Pearce et al., 2016). One basic finding in this field is that the aesthetic appreciation of objects, places, and people emerges from a complex interplay of perceptual, affective, and cognitive processes (Leder \& Nadal, 2014) that are related to activity in neural networks encompassing sensory-areas, cortical and subcortical regions involved in reward processing and prediction, and high-level processing regions, such as the prefrontal cortex (Brown et al., 2011; Chatterjee \& Vartanian, 2014; Nadal, 2013).

One outstanding question is whether both hemispheres are equally involved in the processing of aesthetic features. Clearly, neither hemisphere is solely responsible for the production or appreciation of aesthetics (Zaidel, 2013, 2015). However, hemispheric asymmetries in low-level and highlevel perceptual functions (Hellige, 1993; Hellige, Laeng, \& Michimata, 2010), together with evidence from brain lesion studies (Bromberger, Sternschein, Widick, Smith, \& Chatterjee, 2011), suggest the possibility that some processes underlying aesthetic appreciation are indeed lateralized. In fact, experiments on hemispheric asymmetries in memory and liking for different styles of art suggest that this is the case. Zaidel and Kasher (1989), for example, showed that laypeople recall surrealist paintings with greater accuracy when presented in the right visual field than when presented 
in the left one. No such advantage was observed for realist paintings. This suggests a left hemisphere advantage in processing meaningful but incongruous images (Zaidel \& Kasher, 1989; Zaidel, 1994). Such patterns of asymmetry in memory for artworks can change with acquired expertise, especially in relation to abstract artworks (Vogt \& Magnussen, 2005).

A number of studies have used indirect methods to test for hemispheric asymmetries in preference for artworks. Early studies focused on the association between aesthetic preference and handedness and sex. Van Houten, Chemtob, and Hersh (1981) presented pairs of artworks tachistoscopically to participants' left or right visual field and asked them to judge which artwork in each pair was aesthetically superior. Performance was defined as the degree of similarity to art experts' judgments. Participants classified a priori as "highlylateralized," either on the basis of handedness or sex, showed superior performance in one of the visual fields (there was no systematic pattern supporting either hemisphere's advantage). In turn, judgments of participants classified a priori as "littlelateralized" were equally accurate-i.e., in agreement with those of the experts - irrespective of the visual field in which the artworks were projected. These findings extended prior evidence showing that level of lateralization derived by handedness could predict subjective preference for paintings where the important content was skewed to one side of the image. In particular, Levy (1976) found that right-handers showed a preference for images in which the important content was skewed to the right, probably compensating for their preexisting attentional bias to the left and resulting in a more "balanced" image (Beaumont, 1985; Ellis \& Miller, 1981; McLaughlin, Dean, and Stanley, 1983; Mead and McLaughlin 1992; Valentino et al. 1988). More recently, using a divided visual field (DVF) paradigm, Coney and Bruce (2004) investigated possible lateral asymmetries in aesthetic evaluation of paintings of different styles, finding that they were generally liked more when presented to the right visual field (RVF).

Neuroimaging and electrophysiological evidence also suggests a degree of lateralization in aesthetic judgments, although not always consistent with behavioral data. Using ERP, Jacobsen and Höfel $(2001,2003)$ found that evaluative aesthetic judgments of complex graphic patterns revealed a more pronounced right lateralization compared to descriptive symmetry judgments of the same patterns. The authors argued that such right lateralization may reflect general processing characteristics of evaluative categorization. Using brain stimulation, we have found that modulating activity in the left prefrontal cortex affected aesthetic appreciation of paintings (Cattaneo, Lega, Flexas, et al., 2014), while modulating activity in the right prefrontal cortex influenced the apparent attractiveness of faces (Ferrari et al., 2016). Moreover, symmetry - an important cue in driving the aesthetic judgment - seems to be encoded preferentially in the right hemisphere (Bona, Cattaneo, \& Silvanto, 2015; Bona,
Herbert, Toneatto, Silvanto, \& Cattaneo, 2014; Cattaneo, Mattavelli, Papagno, Herbert, \& Silvanto, 2011).

Three strands of evidence suggest that the role of the two hemispheres in aesthetic appreciation is mediated by participants' sex and the artwork's degree of abstraction. First, men and women differ in their preference for abstract and representational art. Whereas women tend to prefer the representational styles of Impressionism and Rococo more than men, men tend to prefer Cubism and Abstraction more than women (Bernard, 1972; Chamorro-Premuzic, Reimers, Hsu, \& Ahmetoglu, 2009; Frumkin, 1963; Furnham \& Walker, 2001; Savarese \& Miller, 1979).

Second, Cela-Conde et al.'s (2009) MEG study revealed different activity in male and female participants' parietal cortex when judging the beauty of paintings and photographs. In particular, aesthetic appreciation was related to bilateral parietal activity in women and to right hemisphere parietal activity in men (Cela-Conde et al., 2009). This adds to the literature documenting small but reliable sex differences in functional brain asymmetry. Men and women differ in the extent to which brain activity underlying several perceptual and cognitive processes is lateralized. Most studies suggest that functional brain asymmetries are smaller in women than men (Hausmann, 2017). These functional asymmetries seem to be related to anatomical asymmetries: anatomically, women's brains are more symmetrical than men's (Guadalupe et al., 2017; Núñez et al., 2017). Morevoer, female brains have a higher degree of interhemispheric connectivity, whereas male brains have a greater degree of within-hemispheric connectivity. This suggests that male brains are better suited for communicating within the hemispheres and that female brains are better suited for interhemispheric communication (Ingalhalikar et al., 2014)

Third, prior studies have revealed that the appreciation of abstract and representational paintings is mediated by different neural mechanisms. One of the earliest indications was Kettlewell and Lipscomb's (1992) demonstration that people preferring representational and abstract art exhibited different profiles in neuropsychological tests assessing hemispheric asymmetry. The recent use of brain stimulation techniques has produced direct evidence that the appreciation of abstract and representational art relies on different neural mechanisms. For instance, activity in the lateral occipital area contributes more to the appreciation of representational than abstract art (Cattaneo et al., 2015), visual area V5 activity contributes more to the appreciation of abstract than representational art (Cattaneo, Schiavi, Silvanto, \& Nadal, 2017), and left prefrontal cortex is related more to the appreciation of representational art than to abstract art (Cattaneo, Lega, Flexas, et al., 2014; Cattaneo, Lega, Gardelli, et al., 2014).

In the current study we examined the hemispheric lateralization of processes involved in women and men's aesthetic valuation of abstract and representational paintings. Following Coney and Bruce (2004), we used a DVF paradigm. However, the literature 
reviewed in the preceding paragraphs underscores the important mediating role of participants'sex and artworks' degree of abstraction/realism. Thus, whereas Coney and Bruce (2004) tested unequal numbers of female $(n=36)$ and male $(n=4)$ participants, we recruited 40 women and $40 \mathrm{men}$. Also, Coney and Bruce's (2004) materials included many more representational paintings than abstract paintings, whereas we assembled a set of 52 abstract and 52 representational paintings.

\section{Method}

\section{Participants}

Eighty participants ( 40 females, mean age $=22.8 \mathrm{yr}$, standard deviation $[\mathrm{SD}]=2.6$, range $=19-32$ ) with no previous formal or informal training in art volunteered to participate in this study. All were right handed (selective or preferential use of right-hand in all 10 items of the scale - except for item 8 and 10 for "hand indifferent" choice; see Williams, 1986), assessed using Oldfield's (1971) test. All had normal, or corrected-to-normal, vision.

\section{Material and procedure}

Participants sat in front of a 15.5 " PC $(1280 * 800$ pixels $)$ screen at an approximate distance of $57 \mathrm{~cm}$ in a normally lit and silent room and were asked to perform a computerized evaluation task. The stimuli consisted of 104 paintings (52 representational, 52 abstract) belonging to a larger set of images used in previous work (Cela-Conde et al., 2004, 2009). Representational paintings included Realist, Impressionist, and Postimpressionist artworks. Abstract paintings did not include depictions of any recognizable objects. A divided visual field procedure was used, following Bourne's (2006) strict criteria. Figure 1 illustrates the timeline of an experimental trial. Each trial started with a central fixation cross for 500 msec. A painting (subtending approximately $6.5^{\circ} \times 7^{\circ}$ degrees of visual angle) thereafter was presented for $150 \mathrm{~ms}$ located $3^{\circ}$ to the left or $3^{\circ}$ to the right of the fixation cross. Participants had to indicate as fast as possible whether they liked the painting or not. They were instructed to maintain fixation on the central cross, which remained visible throughout the trial until response. Participants responded with their right index and middle finger, with response key assignment for yes/no counterbalanced across participants. Each painting appeared once to the left and once to the right of the central fixation, so that the experiment consisted of 208 trials. Four practice trials were presented before the experiment (using paintings not shown in the experiment) to familiarize participants with the task. Paintings were presented in random order with the exception that the same painting was never shown consecutively. A chinrest was used to ensure that the head was aligned with the middle of the screen and that the distance from the screen was kept constant. Responses ("I like it" Yes/No) and response times (RT) were recorded. E-Prime 2 (Psychology Software Tools, Pittsburgh, PA) was used for stimuli presentation and data collection.

\section{Analysis}

We analyzed the effects of hemifield (left vs. right), artwork category (abstract vs. representational), and sex (men vs. women) on participants' liking responses and response times by means of generalized linear mixed effects models (Hox, 2010; Snijders \& Bosker, 2012). This method accounts simultaneously for the between-subjects and within-subjects effects of the independent variables (Baayen, Davidson, \& Bates, 2008; Judd, Westfall, \& Kenny, 2017). It is especially suitable to study aesthetic appreciation, where people can differ considerably in their responses to different artworks (Silvia, 2007; Brieber, Nadal, Leder, \& Rosenberg, 2014; Cattaneo et al., 2015).

We modelled the impact of hemifield, artwork category, and sex, as well as their interaction, on liking responses and response times. All predictor variables were categorical, and the reference levels were left for hemifield, abstract for artwork category, and women for sex. All predictor variables were deviation coded. We set up both models following Barr, Levy, Scheepers, and Tily's (2013) reccomendation to model the maximal random effects structure justified by the experimental design. In addition to avoiding the loss of power and reducing Type-I error, this enhances the possibility of generalizing results to other participants and stimuli. In sum, both models, the one for liking responses and the one for response times, included the triple interaction between hemifield, artwork category, and sex as fixed effects, and random intercepts and slope for the interaction between hemifield and artwork category within participants, and random intercepts and slope for the interaction between hemifield and sex within stimuli. All analyses were performed within the R environment for statistical computing (R Core Team, 2016). For the analysis of the dichotomous liking responses we used the mixed() function of the 'afex' package (Singmann, Bolker, Westfall, \& Aust, 2016), with likelihood ratio tests to produce the inferential statistics and p-values. For the analysis of response times, we used the lmer() function of the "lme4" package (Bates, Maechler, \& Bolker, 2013) and the "ImerTest" package (Kuznetsova, Brockho, \& Christensen, 2012) to estimate the $p$ values for the $t$ tests based on the Satterthwaite approximation for degrees of freedom. All post-hoc tests were Holm-Bonferroni corrected. All data and R code required for the evaluation and reproduction of the results have been made publicly available online at the Open Science Framework (osf.io/wvd6w). 


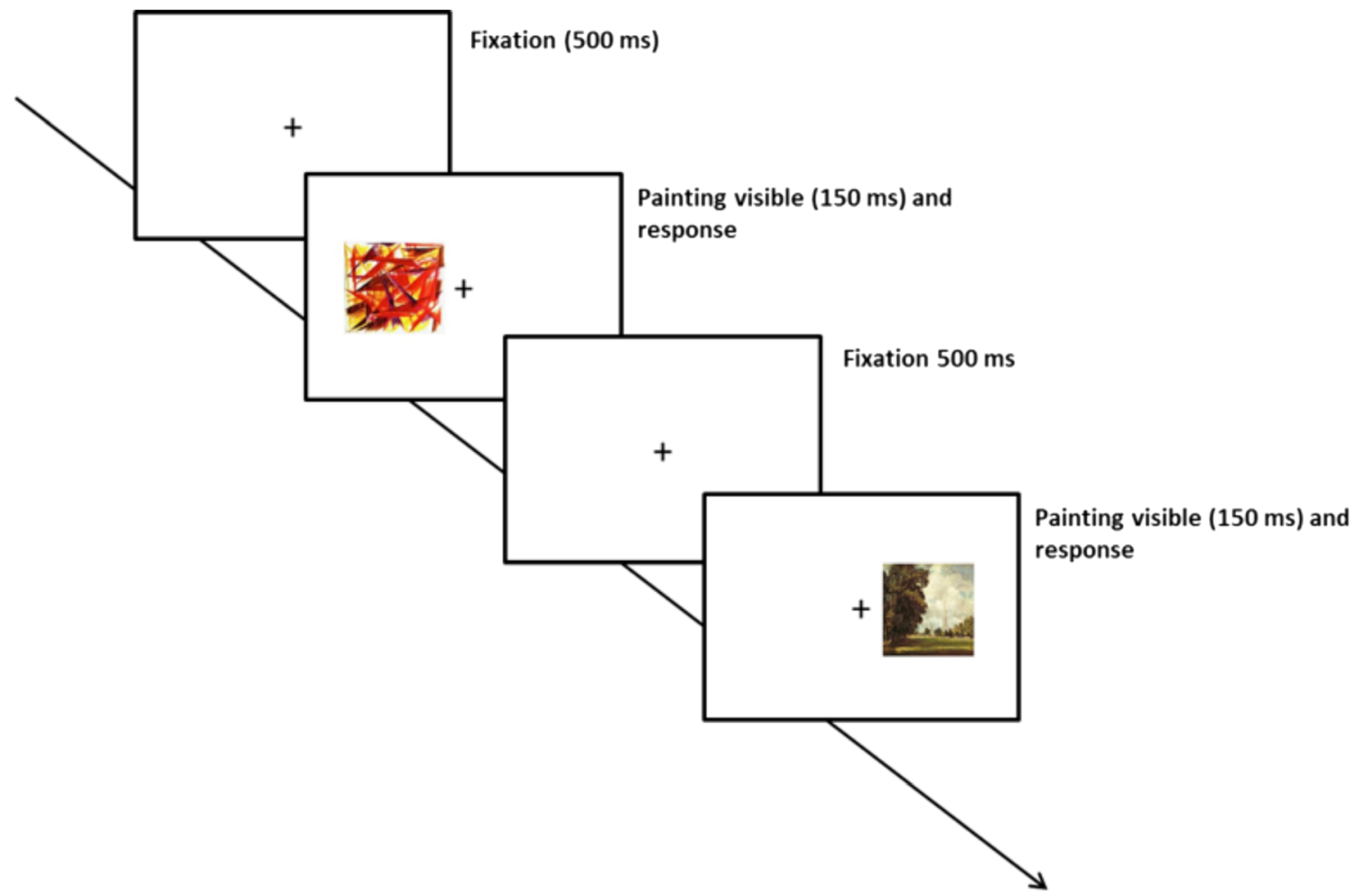

Fig. 1. Timeline of an experimental trial. Participants were presented with a painting of representational or abstract category to the left or right of a central fixation cross and had to indicate whether they liked it as quickly as possible

\section{Results}

Liking responses. We excluded extremely fast $(<200 \mathrm{~ms}$ after stimulus offset) and slow ( $>2,500 \mathrm{~ms}$ after stimulus offset) trials from the analyses. This resulted in the exclusion of less than $1 \%$ of trials). ${ }^{1}$ The results of the linear mixed effects model of liking responses revealed a main effect of artwork category, $\chi^{2}=24.30, p<0.0001$, indicating that participants liked representational artworks $(59.0 \%, 95 \%$ confidence interval $[\mathrm{CI}][53.2,64.6])$ more than abstract artworks $(36.8 \%[31.5,42.5])$. The main effects of hemifield, $\chi^{2}=2.52, p=0.11$, and sex, $\chi^{2}=0.01, p=0.92$, were nonsignificant. The interaction between hemifield and artwork category was significant, $\chi^{2}=8.91, p=0.003$ (Figure 2), indicating that whereas participants liked representational artworks more when presented in the right visual field $(61.6 \%[55.6,67.3])$ than when presented in the left visual field $(56.4 \%[50.2,62.4]), \beta=0.22, z=2.908 p=$ 0.007 , liking for abstract artworks was unaffected by hemifield $(36.7 \%[31.1,42.7]$ when presented in the right, $36.9 \%$ [31.2, 42.8], when presented in the left), $\beta=0.01, z=0.072 p=$ 0.943 (Fig. 2). None of the remaining interactions reached significance, including hemifield by sex, $\chi^{2}=2.35, p=0.13$,

\footnotetext{
${ }^{1}$ Both for the analysis of liking responses and response times, the same pattern of significant and nonsignfican effects holds even if fast and slow trials are not excluded.
}

artwork category by sex, $\chi^{2}=0.08, p=0.77$, and hemifield by artwork category by sex, $\chi^{2}=0.42, p=0.52$.

Response times. As before, extremely fast $(<200 \mathrm{~ms}$ after stimulus offset) and slow responses $(>2,500 \mathrm{~ms}$ after stimulus offset) were excluded from the analysis ( $<1 \%$ of trials). These corresponded to the same trials as those removed for the analysis of liking responses. The linear mixed effects model revealed a trend towards significance for the main effect of artwork category, $\beta=-6.54, t_{(.98)}=1.883, p=0.0627$, indicating that participants tended to respond faster to abstract artworks (560.53 ms after stimulus offset, $95 \%$ CI $529.82,591.25)$ than to representational artworks $(573.25 \mathrm{~ms}[543.51,602.98])$. The main effects of visual field, $\beta=2.345, t_{(73)}=1.106, p=0.272$, and sex, $\beta=-1.448, t_{(78)}=0.097, p=0.922$, were nonsignificant. The interaction between hemifield and artwork category was significant, $\beta=-6.731, t_{(3004)}=3.554, p=0.0004$ (Figure 3), indicating that whereas participants gave faster responses to representational artworks when presented in the right hemifield $(564.31 \mathrm{~ms}[534.65,593.97])$ than when presented in the left $(582.21 \mathrm{~ms}[551.38,613.03]), \beta=18.2, t_{(107.2)}$ $=3.21, p=0.002$, their response times to abstract artworks when presented in the left hemifield $(556.15 \mathrm{~ms}$ [523.79, $588.52])$ and when presented in the right (564.90 $\mathrm{ms}$ [534.86, 594.94]) did not differ significantly, $\beta=-8.8, t_{(124.9)}=1.53, p=$ 0.128 (Fig. 3). None of the remaining interactions reached significance, including hemifield by sex, $\beta=-1.540, t_{(73)}=0.727$, $p=0.470$, artwork category by sex, $\beta=4.893, t_{(69)}=1.627, p=$ 


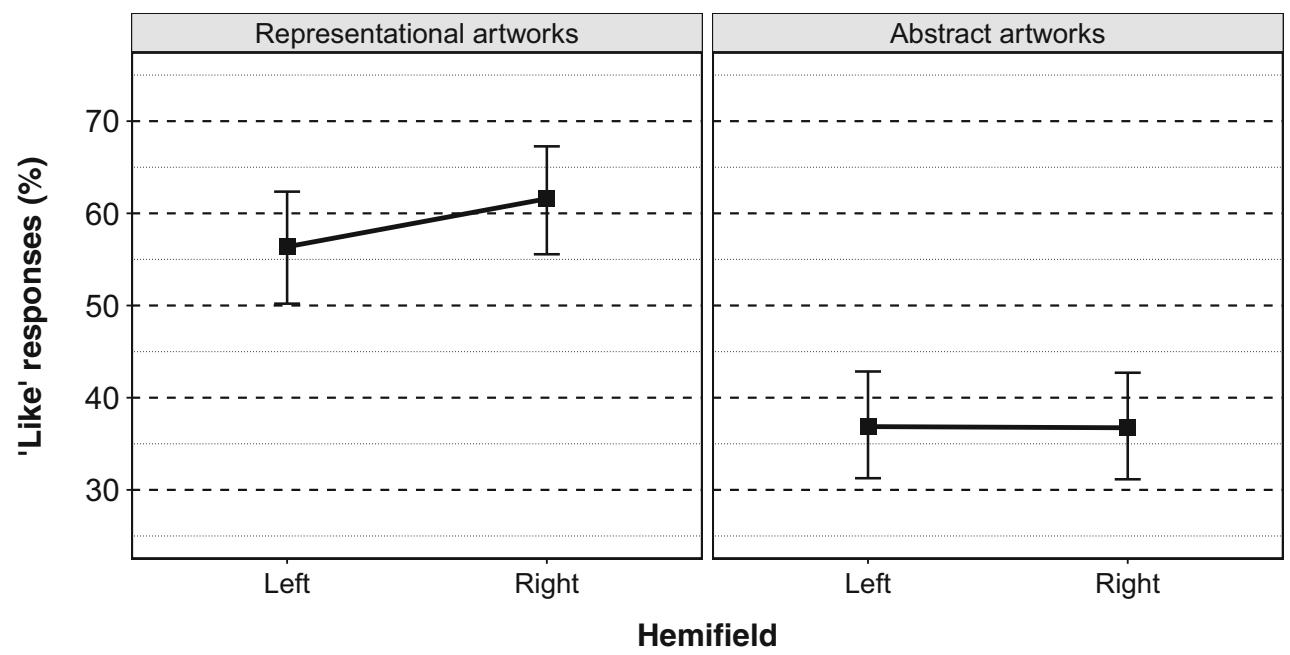

Fig. 2. Percentage of "I like it" responses as a function of artwork category and visual field in which the paintings appeared. Error bars depict $95 \%$ confidence intervals

0.108 , and hemifield by artwork category by sex, $\beta=1.901$, $t_{(3435)}=1.004, p=0.315$.

\section{Discussion}

The past two decades have seen a growing interest in the neural underpinnings of aesthetic preference (Chatterjee, 2011; Pearce et al., 2016). In this time, it has become clear that aesthetic preference is related to activity in neural networks involved in perceptual analyses, emotion and affect, and meaning and understanding (Chatterjee \& Vartanian, 2014; Nadal, 2013). One issue that remains relatively unexplored is that of the hemispheric lateralization of the processing of features relevant to aesthetic preference (Coney \& Bruce, 2004; Zaidel, 2015). In this study, we used a divided visual field paradigm to test for hemispheric asymmetries in men and women's preference for abstract and representational artworks.

We included abstract and representational artworks because studies have shown that people respond differently to them and that their appreciation engages different neural processes (Cattaneo, Lega, Flexas, et al., 2014; Cattaneo et al., 2015; Fairhall \& Ishai, 2008). Indeed, in line with previous experiments, we found that participants liked representational artworks more than abstract artworks (Cattaneo et al., 2015; Furnham and Walker, 2001; Kettlewell et al., 1990; Knapp and Wulff, 1963; Pihko et al., 2011). This common finding is generally attributed to laypeople's approach to art, which can be conceived as an extension of general viewing and perceptual processes (Cupchik \& Gebotys, 1988). Laypeople lack experts' knowledge and schemas that allow them to extract meaning from artworks' style, expressive use of the medium, allusions to other artworks, etc. Thus, they base their

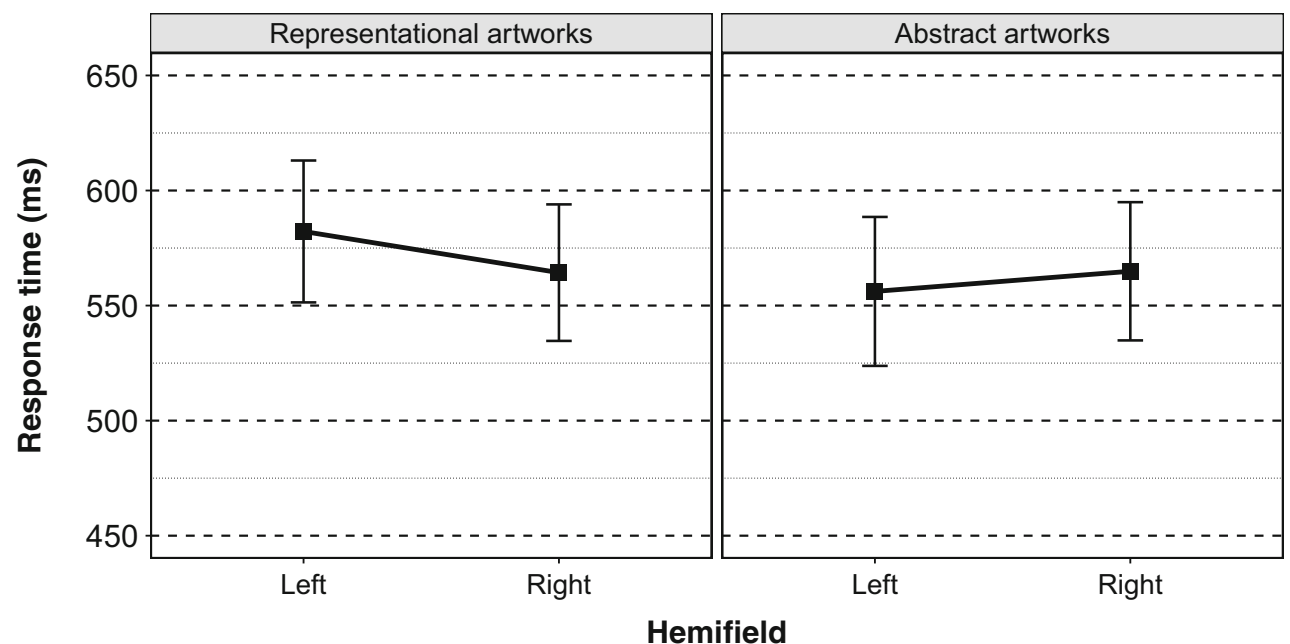

Fig. 3. Response times (after stimulus offset, in $\mathrm{ms}$ ) as a function of artwork category and visual field in which the paintings appeared. Error bars depict $95 \%$ confidence intervals 
viewing of art mainly on object schemas, and search for recognizable elements that can elicit pleasant associations. Given that, by definition, abstract art does not depict immediately identifiable objects, laypeople, such as our participants, usually find little that fits their object schemas, and therefore, little to elicit the pleasant feelings they expect from artworks. Representational artworks, conversely, offer laypeople the chance for understanding, if not the artwork itself, at least the depicted scene.

Our main finding showed that, independently of their sex, participants liked representational paintings more when presented in the right visual field and that liking for abstract paintings was unaffected by presentation hemifield. These results suggest that certain processes underlying laypeople's liking for representational art are hemispherically lateralized. But which processes? Two separate strands of research converge on a suggestive possibility. First, eye tracking experiments of art appreciation have shown that when laypeople look at representational paintings they adopt a local, rather than global, viewing strategy. They fixate mostly on informative details of recognizable objects, rather than on background features or on the relations among objects (Nodine, Locher, \& Krupinski, 1993; Vogt, 1999; Vogt \& Magnussen, 2007; Zangemeister, Sherman, Stark, 1995). This strategy yields little of value for the appreciation of abstract art, where the foregroundbackground distinction is blurred, and where a local viewing strategy reveals nothing but meaningless and disjointed patches and brushstrokes of paint. Second, behavioral, brain lesion, and brain imaging studies have shown that both hemispheres differ in the extent to which they are involved in processing local and global features of visual stimuli. Specifically, the left hemisphere is relatively specialized in processing the local details of visual stimuli (as well as topological properties, see Wang, Zhou, Zhuo, \& Chen, 2007) and in determining whether objects belong to given categories; the right hemisphere is relatively specialized in processing the global or configural properties (Fink et al., 1997; Hellige et al., 2010; Hübner, 1998; Van Kleeck, 1989; see also Cattaneo, Renzi, et al., 2014b; Renzi et al., 2013, for hemispheric specialization in configural vs. featural processing of faces).

Weaving these two strands together, we hypothesize that certain processes involved in the performance of the liking task - specifically, participants' search for recognizable informative features - are facilitated when representational artworks were presented in the right visual field, given the left hemisphere's advantage in processing such local features. This interpretation also is congruent with participants' faster responses when representational artworks were presented in the right visual field than when presented in the left visual field.

Our results are in line with Coney and Bruce's (2005). Both studies reported increased liking when artworks were presented in the right visual field. However, whereas Coney and Bruce (2004) found that presentation hemifield mainly influenced liking for modern artworks (including abstract paintings) but not traditional artworks, we found that it influenced liking for representational but not abstract artworks. Several reasons might account for this discrepancy. First, the stimuli categories in both studies do not overlap. Our set of representational artworks includes styles that cluster as modern art (Cubism and Expressionism) and as traditional art (Renaissance and Impressionism) in Coney and Bruce's (2004) study. Second, our set of stimuli includes works by renowned artists, but an effort was made to exclude familiar pieces, especially those that are usually exhibited at museums (Cela-Conde et al., 2004, 2009). Conversely, the images in Coney and Bruce's (2004) set "were selected from among those currently on display in museums and galleries around the world" (Coney \& Bruce, 2004, p. 187). Thus, both stimuli sets might differ as to the familiarity of the works included. Third, whereas Coney and Bruce (2005) explicitly "invited participants to rate their emotional reaction to the stimuli" (Coney \& Bruce, 2004, p. 194), we gave no such indication to our participants, and in fact, the set of images that we used exluded works that could evoke strong emotional responses (Cela-Conde et al., 2004, 2009). Thus, it is possible that whereas the materials and instructions in Coney and Bruce's (2004) study prompted participants to focus on the emotional aspect of their experience of familiar artworks, our materials and instructions prompted participants to focus on the more perceptual features of unfamiliar artworks.

When interpreting our results, it is worth noting that we did not monitor eye movements. We therefore cannot exclude that in certain trials participants directly looked at paintings. However, this is unlikely, because we clearly instructed participants and reminded them throughout the task (note that the experimenter sat near the participant during testing) of the importance of maintaining central fixation. Moreover, we minimised the possibility of the test stimulus being foveated by presenting stimuli for a very short time and randomly in the left or right visual field to discourage anticipatory saccades away from central fixation (Bourne, 2006). Conversely, if participants directly looked at paintings, it would be difficult to explain why visual field differences then emerged and only in certain conditions (representational paintings). Nevertheless, future studies may control for central fixation maintenance better, thus possibly reducing undesired sources of variability in the data.

\section{Conclusions}

Both men and women liked representational artworks more when presented in the right visual field than when presented in the left visual field. Liking for abstract artworks was 
unaffected by presentation hemifield. We have hypothesized that this effect is due to the facilitation of the sort of visual processes relevant to laypeople's liking for art—specifically, local processing of highly informative object features - when artworks are presented in the right visual field, given the left hemisphere's advantage in processing such features. Further studies are required to clarify the potential mediating role of artistic style, familiarity, and emotional investment.

Acknowledgements Marcos Nadal was supported by grant PSI201677327-P, awarded by the Spanish Ministerio de Economía, Industria y Competitividad. Zaira Cattaneo was supported by a Fund for Investments on basic Research (FIRB), Italian Ministry of Education, University and Research (RBFR12F0BD).

All data and $\mathrm{R}$ code required for the evaluation and reproduction of the results have been made publicly available online at the Open Science Framework (osf.io/wvd6w). The artworks used as stimuli cannot be made publicly available due to owners' copyright restrictions.

\section{References}

Baayen, R. H., Davidson, D. J., \& Bates, D. M. (2008). Mixed-effects modeling with crossed random effects for subjects and items. Journal of Memory and Language, 59, 390-412.

Balling, J. D., \& Falk, J. H. (1982). Development of visual preference for natural environments. Environment and Behavior, 14, 5-28.

Barr, D. J., Levy, R., Scheepers, C., \& Tily, H. J. (2013). Random effects structure for confirmatory hypothesis testing: Keep it maximal. Journal of Memory and Language, 68, 255-278.

Bates, D., Maechler, M., \& Bolker, B. (2013). lme4: Linear mixed-effects models using S4 classes, R package version 0.999999-2. http://cran. rproject.org/web/packages/lme4/index.html.

Beaumont, G. J. (1985). Lateral organization and aesthetic preference: The importance of peripheral visual asymmetries. Neuropsychologia, 23, 103-113.

Bernard, Y. (1972). Sex influence in aesthetic behavior. Perceptual and Motor Skills, 34, 663-666.

Bona S., Cattaneo Z., \& Silvanto, J. (2015).The causal role of the occipital face area (OFA) and lateral occipital (LO) cortex in symmetry perception. Journal of Neuroscience, 35(2): 731-738.

Bona, S., Herbert, A., Toneatto, C., Silvanto, J., \& Cattaneo, Z. (2014). The causal role of the lateral occipital complex in visual mirror symmetry detection and grouping: an fMRI-guided TMS study. Cortex, 51:46-55.

Bourne, V. J. (2006). The divided visual field paradigm: methodological considerations. Laterality, 11(4), 373-393. https://doi.org/10.1080/ 13576500600633982

Brieber, D., Nadal, M., Leder, H., \& Rosenberg, R. (2014). Art in time and space: Context modulates the relation between art experience and viewing time. PLoS One, 9(6): e99019. https://doi.org/10.1371/ journal.pone.0099019.

Bromberger, B., Sternschein, R., Widick, P., Smith II, W., \& Chatterjee, A. (2011). The right hemisphere in esthetic perception. Frontiers in Human Neuroscience, 5, 109. https://doi.org/10.3389/fnhum.2011. 00109.

Brown, S., Gao, X., Tisdelle, L., Eickhoff SB, \& Liotti, M. (2011). Naturalizing aesthetics: Brain areas for aesthetic appraisal across sensory modalities. Neuroimage, 58, 250-258.

Cattaneo, Z., Lega, C., Ferrari, C., Vecchi, T., Cela-Conde, C. J., Silvanto, J., \& Nadal, M. (2015). The role of the lateral occipital cortex in aesthetic appreciation of representational and abstract paintings: A TMS study. Brain and Cognition, 95, 44-53.

Cattaneo, Z., Lega, C., Flexas, A., Nadal, M., Munar, E., \& Cela-Conde, C. J. (2014a). The world can look better: enhancing beauty experience with brain stimulation. Social Cognitive and Affective Neuroscience, 9, 1713-1721. https://doi.org/10.1093/scan/nst165

Cattaneo, Z., Lega, C., Gardelli, C., Merabet, L. B., Cela-Conde, C. J., \& Nadal, M. (2014b). The role of prefrontal and parietal cortices in esthetic appreciation of representational and abstract art: A TMS study. NeuroImage, 99, 443-450. https://doi.org/10.1016/j. neuroimage.2014.05.037.

Cattaneo, Z., Mattavelli, G., Papagno, C., Herbert, A.M., \& Silvanto, J. (2011). The role of the human extrastriate visual cortex in mirror symmetry discrimination: A TMS adaptation study. Brain and Cognition, 77(1), 120-127.

Cattaneo, Z., Renzi, C., Bona, S., Merabet, L. B., Carbon, C.-C., \& Vecchi, T. (2014c). Hemispheric asymmetry in discriminating faces differing for featural or configural (second-order relations) aspects. Psychonomic Bulletin \& Review, 21,363-9. https://doi.org/10.3758/ s13423-013-0484-2.

Cattaneo, Z., Schiavi, S., Silvanto, J., \& Nadal, M. (2017). A TMS study on the contribution of visual area V5 to the perception of implied motion in art and its appreciation. Cognitive Neuroscience, 8, 59-68. https://doi.org/10.1080/17588928.2015.1083968

Cela-Conde, C. J., Ayala, F. J., Munar, E., Maestú, F., Nadal, M., Capó, M. a., ... Marty, G. (2009). Sex-related similarities and differences in the neural correlates of beauty. Proceedings of the National Academy of Sciences of the United States of America, 106(10), 3847-3852. https://doi.org/10.1073/pnas.0900304106

Cela-Conde, C. J., Marty, G., Maestú, F., Ortiz, T., Munar, E., Fernandez, A., ... Quesney, F. (2004). Activation of the prefrontal cortex in the human visual aesthetic perception. Proceedings of the National Academy of Sciences of the United States of America, 101(16), 6321-6325. https://doi.org/10.1073/pnas.0401427101.

Chamorro-Premuzic, T., Reimers, S., Hsu, A., \& Ahmetoglu, G. (2009). Who art thou? Personality predictors of artistic preferences in a large UK sample: The importance of openness. British Journal of Psychology, 100, 501-516.

Chatterjee, A. (2011). Neuroaesthetics: A coming of age story. Journal of Cognitive Neuroscience, 23, 53-62.

Chatterjee, A., \& Vartanian, O. (2014). Neuroaesthetics. Trends in Cognitive Sciences, 18(7), 370-375. https://doi.org/10.1016/j.tics. 2014.03.003

Choo, H., Nasar, J. L., Nikrahei, B., \& Walther, D. B. (2017). Neural codes of seeing architectural styles. Scientific Reports, 7, 40201. https://doi.org/10.1038/srep40201

Coney, J., \& Bruce, C. (2004). Hemispheric Processes in the Perception of Art. Empirical Studies of the Arts, 22(2), 181-200. https://doi.org/ 10.2190/39EN-YCVM-M30K-W6H8

Cupchik, G. C., \& Gebotys, R. J. (1988). The search for meaning in art: Interpretive styles and judgments of quality. Visual Arts Research, $14,38-58$.

Ellis, A. E., \& Miller, D. (1981). Left and wrong in adverts: Neuropsychological correlates of aesthetic preference. British Journal of Psychology, 72, 225-229.

Fairhall, S. L., \& Ishai, A. (2008). Neural correlates of object indeterminacy in art compositions. Consciousness and Cognition, 17, 923932. https://doi.org/10.1016/j.concog.2007.07.005

Ferrari, C., Lega, C., Vernice, M., Tamietto, M., Mende-Siedlecki, P., Vecchi, T., Todorov, A., \& Cattaneo, Z. (2016). The dorsomedial prefrontal dortex plays a causal role in integrating social impressions from faces and verbal descriptions. Cerebral Cortex, 26, 156-165.

Fink, G. R., Halligan, P. W., Marshall, J. C., Frith, C. D., Frackowiak, R. S. J., \& Dolan, R. J. (1997). Neural mechanisms involved in the processing of global and local aspects of hierarchically organized visual stimuli. Brain, 120, 1779-1791. 
Frumkin, R. M. (1963). Sex, familiarity, and dogmatism as factors in painting preferences. Perceptual and Motor Skills, 17(1), 12.

Furnham, A., \& Walker, J. (2001). The influence of personality traits, previous experience of art, and demographic variables on artistic preference. Personality and Individual Differences, 31, 997-1017.

Guadalupe, T., Mathias, S. R., vanErp, T. G. M., Whelan, C. D., Zwiers, M. P., Abe, Y., . . . Francks, C. (2017). Human subcortical brain asymmetries in 15,847 people worldwide reveal effects of age and sex. Brain Imaging and Behavior, in press. https://doi.org/10.1007/ s11682-016-9629-z

Hausmann, M. (2017). Why sex hormones matter for neuroscience: a very short review on sex, sex hormones, and functional brain asymmetries. Journal of Neuroscience Research, 95, 40-49.

Hellige, J. B. (1993). Hemispheric asymmetry: What's right and what's left. Cambridge, MA: Harvard University Press.

Hellige, J. B., Laeng, B., \& Michimata, C. (2010). Processing asymmetries in the visual system. In K. Hugdahl \& R. Westerhausen (Eds.), The two halves of the brain. Information processing in the cerebral hemispheres (pp. 379-415). Cambridge, MA: The MIT Press.

Ho, C.-H., Lu, Y.-N., \& Chen, C.-H. (2016). Influence of curvature and expertise on aesthetic preferences for mobile device designs. International Journal of Design, 10, 17-25.

Hox, J. J. (2010). Multilevel analysis. Techniques and applications (Second ed.). New York: Routledge.

Hübner, R. (1998). Hemispheric differences in global/local processing revealed by same-different judgments. Visual Cognition, 5, 457-478.

Ingalhalikar, M., Smith, A., Parker, D., Satterthwaite, T. D., Elliott, M. A., Ruparel, K., . . Verma, R. (2014). Sex differences in the structural connectome of the human brain. Proceedings of the National Academy of Sciences, USA, 111, 823-828.

Jacobsen, T. \& Höfel, L. (2001). Aesthetics electrified: An analysis of descriptive symmetry and evaluative aesthetic judgment processes using event-related brain potentials. Empirical Studies of the Arts, 19(2), 177-190.

Jacobsen, T. \& Höfel, L. (2003). Descriptive and evaluative judgment processes: Behavioral and electrophysiological indices of processing symmetry and aesthetics. Cognitive, Affective, \& Behavioral Neuroscience 3(4), 289-299.

Judd, C. M., Westfall, J., \& Kenny, D. A. (2017). Experiments with more than one random factor: designs, analytic models, and statistical power. Annual Review of Psychology, 68, 601-625.

Kampe, K. K., Frith, C. D., Dolan, R. J., \& Frith, U. (2001). Reward value of attractiveness and gaze. Nature, 413, 589 .

Kaplan, S. (1992). Environmental preference in a knowledge-seeking, knowledge-using organism. In J. H. Barkow, L. Cosmides \& J. Tooby (Eds.), The Adapted Mind: Evolutionary Psychology and the Generation of Culture (pp. 581-598). New York, NY: Oxford University Press.

Kettlewell, N., \& Lipscomb, S. (1992). Neuropsychological correlates for realism-abstraction, a dimension of aesthetics. Perceptual and Motor Skills, 75, 1023-1026.

Kettlewell, N., Lipscomb, S., Evans, L., \& Rosston, K. (1990). The effect of subject matter and degree of realism on aesthetic preferences for paintings. Empirical Studies of the Arts, 8, 85-93.

Kirk, U., Skov, M., Christensen, M. S., \& Nygaard, N. (2009). Brain correlates of aesthetic expertise: A parametric fMRI study. Brain and Cognition, 69, 306-315.

Knapp, R. H., \& Wulff, A. (1963). Preferences for abstract and representational art. The Journal of Social Psychology, 60, 255-262.

Kuznetsova, A., Brockho, P. B., \& Christensen, R. H. B. (2012). lmerTest: Tests for random and fixed effects for linear mixed effect models (lmer objects of lme4 package). http://www.cran.r-project. org/package=lmerTest/.

Leder, H., \& Nadal, M. (2014). Ten years of a model of aesthetic appreciation and aesthetic judgments: The aesthetic episode- developments and challenges in empirical aesthetics. British Journal of Psychology, 105, 443-464. https://doi.org/10.1111/bjop. 12084

Leder, H., Tinio, P. P. L., Fuchs, I. M., \& Bohrn, I. (2010). When attractiveness demands longer looks: The effects of situation and gender. The Quarterly Journal of Experimental Psychology, 63, 1858-1871.

Levy, J. (1976). Lateral dominance and aesthetic preference. Neuropsychologia, 14, 431-445.

McLaughlin, J. P., Dean, P., \& Stanley, P. (1983). Aesthetic preference in dextrals and sinistrals. Neuropsychologia, 21, 147-153.

Mead, A. M., \& McLaughlin, J. P. (1992). The roles of handedness and stimulus asymmetry in aesthetic preference. Brain and Cognition, 20, 300-307. https://doi.org/10.1016/0278-2626(92)90022-E

Mende-Siedlecki, P., Said, C. \& Todorov, A. (2012). The social evaluation of faces: a meta-analysis of functional neuroimaging studies. Social Cognitive and Affective Neuroscience, 8, 285-299. https://doi. org $/ 10.1093 / \mathrm{scan} / \mathrm{nsr} 090$

Nadal, M. (2013). The experience of art: Insights from neuroimaging. Progress in Brain Research, 204, 135-158.

Nodine, C. F., Locher, P. J., \& Krupinski, E. A. (1993). The role of formal art training on perception and aesthetic judgment of art compositions. Leonardo, 26, 219-227.

Núñez, C., Theofanopoulou, C., Senior, C., Cambra, M. R., Usall, J., Stephan-Otto, C., \& Brébion, G. (2017). A large-scale study on the effects of sex on gray matter asymmetry. Brain Structure \& Function, in press. https://doi.org/10.1007/s00429-017-1481-4

Oldfield, R. C. (1971). The assessment and analysis of handedness: the Edinburgh inventory. Neuropsychologia, 9(1), 97-113.

Patrick, V. M. (2016). Everyday consumer aesthetics. Current Opinion in Psychology, 10, 60-64.

Pearce, M. T., Zaidel, D. W., Vartanian, O., Skov, M., Leder, H., Chatterjee, A., \& Nadal, M. (2016). Neuroaesthetics: The cognitive neuroscience of aesthetic experience. Perspectives on Psychological Science, 11, 265-279.

Pihko, E., Virtanen, A., Saarinen, V.-M., Pannasch, S., Hirvenkari, L., Tossavainen, T., . . . Hari, R. (2011). Experiencing art: the influence of expertise and painting abstraction level. Frontiers in Human Neuroscience, 5, https://doi.org/10.3389/fnhum.2011.00094.

R Core Team. (2016). R: A language and environment for statistical computing. Vienna, Austria: R Foundation for Statistical Computing. Retrieved from http://www.R-project.org

Reimann, M., Zaichkowsky, J., Neuhaus, C., Bender, T., \& Weber, B. (2010). Aesthetic package design: A behavioral, neural, and psychological investigation. Journal of Consumer Psychology, 20(4), 431441. DOI: https://doi.org/10.1016/j.jcps.2010.06.009

Renzi, S., Schiavi, S., Carbon, C.C., Vecchi, T., Silvanto, J., \& Cattaneo Z (2013). Processing of featural and configural aspects of faces is lateralized in dorsolateral prefrontal cortex: a TMS study. Neuroimage, 74, 45-51.

Savarese, J. M., \& Miller, R. J. (1979). Artistic preferences and cognitiveperceptual style. Studies in Art Education, 20, 45-41.

Silvia, P. J. (2007). An introduction to multilevel modeling for research on the psychology of art and creativity. Empirical Studies of the Arts, $25,1-20$

Singmann, H., Bolker, B., Westfall, J., \& Aust, F. (2016). afex: Analysis of Factorial Experiments. R package version 0.18-0. https://CRAN. R-project.org/package $=$ afex.

Snijders, T. A. B., \& Bosker, R. J. (2012). Multilevel analysis. An introduction to basic and advanced multilevel modeling (Second ed.) London: SAGE Publications.

Townsend, C., \& Shu, S. B. (2010). When and how aesthetics influences financial decisions. Journal of Consumer Psychology, 20, 452-458.

Valentino, M. A., Brown, J. W., \& Cronan-Hillix, W. A. (1988). Aesthetic preference and lateral dominance. Perceptual and Motor Skills, (1950), 555-561. 
Van Houten, W. H., Chemtob, C. M., \& Hersh, S. I. (1981). Hemispheric lateralization and aesthetic judgement. Cortex, 17(4), 477-489. https://doi.org/10.1016/S0010-9452(81)80056-1.

Van Kleeck, M. H. (1989). Hemispheric differences in global versus local processing of hierarchical visual stimuli by normal subjects: new data and a meta-analysis of previous studies. Neuropsychologia, 27, 1165-1178.

Vartanian, O., Navarrete, G., Chatterjee, A., Fich, L. B., González-Mora, J. L., Leder, H., . . Skov, M. (2015). Architectural design and the brain: Effects of ceiling height and perceived enclosure on beauty judgments and approach-avoidance decisions. Journal of Environmental Psychology, 41, 10-18.

Vogt, S. (1999). Looking at paintings: Patterns of eye movements in artistically naïve and sophisticated subjects. Leonardo, 32, 325.

Vogt, S., \& Magnussen, S. (2005). Hemispheric specialization and recognition memory for abstract and realistic pictures: A comparison of painters and laymen. Brain and Cognition, 58, 324-333.

Vogt, S., \& Magnussen, S. (2007). Expertise in pictorial perception: eyemovement patterns and visual memory in artists and laymen. Perception, 36, 91-100.
Wang, B., Zhou, T.G., Zhuo, Y, Chen, L. (2007). Global topological dominance in the left hemisphere. Proceedings of the National Academy of Sciences of the United States of America, (52):21014-9.

Williams, S. M. (1986). Factor analysis of the Edinburgh Handedness Inventory. Cortex, 22, 325-326.

Zaidel, D. W. (1994). Words apart: Pictorial semantics in the left and right cerebral hemispheres. Current Directions in Psychological Science, $3,5-8$.

Zaidel, D. W. (2013). Split-brain, the right hemisphere, and art: Fact and fiction. Progress in Brain Research, 204, 3-17.

Zaidel, D. W. (2015). Hemispheric specialization, art, and aesthetics. In J. P. Huston, M. Nadal, F. Mora, L. F. Agnati \& C. J. Cela-Conde (Eds.), Art, aesthetics and the brain (pp. 373-382). Oxford: Oxford University Press.

Zaidel, D. W., \& Kasher, A. (1989). Hemispheric memory for surrealist versus realistic paintings. Cortex, 25, 617-641.

Zangemeister, W. H., Sherman, K., \& Stark, L. (1995). Evidence for a global scanpath strategy in viewing abstract compared with realistic images. Neuropsychologia, 33, 1009-1025. 